\title{
Persistence of dysfunctional natural killer cells in adults with high-functioning autism spectrum disorders: stigma/consequence of unresolved early infectious events?
}

Meriem Bennabi ${ }^{1,2,4 \dagger}$, Nadine Tarantino ${ }^{3 \dagger}$, Alexandru Gaman ${ }^{2,4}$, Isabelle Scheid ${ }^{2,4}$, Rajagopal Krishnamoorthy ${ }^{1}$, Patrice Debré, ${ }^{3}$ Arthur Bouleau ${ }^{4}$, Mireille Caralp ${ }^{5,6}$, Sonia Gueguen ${ }^{5,6}$, Myriam Ly Le-Moal ${ }^{7}$, Manuel Bouvard ${ }^{2,8}$, Anouck Amestoy ${ }^{2,8}$, Richard Delorme ${ }^{2,9}$, Marion Leboyer ${ }^{2,4^{*}+}$, Ryad Tamouza ${ }^{1,2,4+}$ and Vincent Vieillard ${ }^{3^{*}+}$

\begin{abstract}
Background: Autism spectrum disorders (ASD) are characterized by abnormal neurodevelopment, genetic, and environmental risk factors, as well as immune dysfunctions. Several lines of evidence suggest alterations in innate immune responses in children with ASD. To address this question in adults with high-functioning ASD (hf-ASD), we sought to investigate the role of natural killer (NK) cells in the persistence of ASD.

Methods: NK cells from 35 adults with hf-ASD were compared to that of 35 healthy controls (HC), selected for the absence of any immune dysfunctions, at different time-points, and over a 2-year follow-up period for four patients. The phenotype and polyfunctional capacities of NK cells were explored according to infectious stigma and clinical parameters (IQ, social, and communication scores).
\end{abstract}

Results: As compared to HC, NK cells from patients with hf-ASD showed a high level of cell activation $(p<0.0001)$, spontaneous degranulation $(p<0.0001)$, and interferon-gamma production $(p=0.0004)$, whereas they were exhausted after in vitro stimulations $(p=0.0006)$. These data yielded a specific HLA-DR ${ }^{+} K I R 2 D L 1^{+} N K G 2 C^{+} N K$-cell signature. Significant overexpression of NKG2C in hf-ASD patients $(p=0.0005)$, indicative of viral infections, was inversely correlated with the NKp46 receptor level $(r=-0.67 ; p<0.0001)$, regardless of the IgG status of tested pathogens. Multivariate linear regression analysis also revealed that expression of the late-activating HLA-DR marker was both associated with structural language $(r=0.48 ; p=0.007)$ and social awareness $(r=0.60 ; p=0.0007)$ scores in adult patients with hf-ASD, while KIR2DL1 expression correlated with IQ scores $(p=0.0083)$.

Conclusions: This study demonstrates that adults with hf-ASD have specific NK-cell profile. Presence of NKG2C overexpression together with high-level activation of NK cells suggest an association with underlying pathogens, a hypothesis warranting further exploration in future studies.

Keywords: Autism spectrum disorders, High-functioning autism, Natural killer cells, Pathogens

\footnotetext{
* Correspondence: marion.leboyer@inserm.fr; vincent.vieillard@sorbonneuniversite.fr

Meriem Bennabi and Nadine Tarantino contributed equally to this paper. Marion Leboyer, Ryad Tamouza, and Vincent Vieillard contributed equally to this paper, as senior co-author.

${ }^{2}$ Fondation FondaMental, Créteil, France

${ }^{3}$ Sorbonne Université, UPMC, INSERM U1135, CNRS ERL8255, Centre

d'Immunologie et des Maladies Infectieuses (CIMI-Paris), Paris, France

Full list of author information is available at the end of the article
}

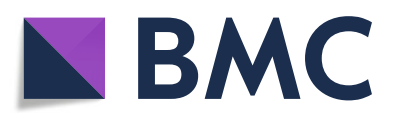

(c) The Author(s). 2019 Open Access This article is distributed under the terms of the Creative Commons Attribution 4.0 International License (http://creativecommons.org/licenses/by/4.0/), which permits unrestricted use, distribution, and reproduction in any medium, provided you give appropriate credit to the original author(s) and the source, provide a link to the Creative Commons license, and indicate if changes were made. The Creative Commons Public Domain Dedication waiver (http://creativecommons.org/publicdomain/zero/1.0/) applies to the data made available in this article, unless otherwise stated. 


\section{Introduction}

Autism spectrum disorders (ASD) are heterogeneous neurodevelopmental conditions characterized by deficits in social interactions and repetitive patterns of behavior and interests $[1,2]$. The number of reported ASD cases has dramatically increased in recent years, reaching an alarming level of 1 in 68 children in the USA, which represents a 25-fold increase between 1970 and 2012 $[3,4]$. Although contributions of several genetic and environmental factors are now well accepted, the etiopathogenesis of ASD remains largely unknown [5]. Immune dysfunction, as reflected by a pro-inflammatory status, is regarded as a significant driver of ASD pathology. Such immune alterations underpinning ASD risk may be driven by maternal infections during the pre-/perinatal period [6-10], possibly interacting with specific immunogenetic backgrounds, such as MET, also called hepatocyte growth factor receptor (HGFR) and human leukocyte antigen (HLA) [11-14]. Together, several alterations in cellular immunity have also been reported in ASD, including a skewed adaptive $\mathrm{T}$ cell response toward a $\mathrm{T}$ helper 2 phenotype and changes in the cytotoxicity of natural killer (NK) cells [15-17]. Both alterations in immune responses may contribute to an inefficient anti-infectious response, thereby allowing infections to have a significant impact on ASD risk and etiopathogenesis [18]. However, the vast majority of studies have investigated responses in young affected children, with very little information on innate abnormalities, particularly in adults and in high-functioning patients.

NK cell immune subsets constitute a unique niche, given their bridging roles between innate and adaptive immune processes. Upon detection of generic cellular stress signals, transformation, or infection, NK cells acquire immediate effector functions. During infections, NK cells are the critical effectors of innate antiviral immune responses, as demonstrated in cases of inherited NK deficiencies [19]. During immune surveillance, NK cells distinguish their cellular targets from healthy cells via a panel of activating and inhibitory receptors, which recognize ligands specifically induced on "stressed" cells [20]. When activating signals predominate, NK cells produce an array of pro-inflammatory cytokines, such as interferon-gamma (IFN- $\gamma$ ) and tumor necrosis factoralpha (TNF- $\alpha$ ), in parallel to the initiation of their cytotoxic functions [21-23].

Several lines of evidence indicate that NK cells play a role in ASD. Ashwood et al. [24] reported that the absolute count of NK cells was approximately $40 \%$ higher in children with low- and high-functioning ASD (hf-ASD), compared to healthy controls. This result is concordant with other studies on children with ASD [15-17]. Interestingly, this increase in NK cells is associated with a deficient response following in vitro stimulation [16], despite the
Table 1 Demographic and clinical data of patients with hf-ASD

\begin{tabular}{|c|c|}
\hline Characteristics & ASD \\
\hline Number & 35 \\
\hline Mean age in years (range) & $30(18-56)$ \\
\hline Ratio, male to female & $27: 8$ \\
\hline Mean IQ value (range) & $105(70-146)$ \\
\hline \multicolumn{2}{|l|}{ Communication Checklist for Adults scale (CCA) } \\
\hline CCA-LS, (range, mean \pm SD) & $(2-39), 11 \pm 9$ \\
\hline CCA-PS, (range, mean \pm SD) & $(1-50), 18 \pm 11$ \\
\hline CCA-SE, (range, mean $\pm \mathrm{SD}$ ) & $(21-57), 37 \pm 9$ \\
\hline \multicolumn{2}{|l|}{ Social Responsiveness Scale (SRS) } \\
\hline SAWR, (range, mean \pm SD) & $(41-92), 60 \pm 12$ \\
\hline SCOG, (range, mean \pm SD) & $(41-95), 65 \pm 12$ \\
\hline SCOM, (range, mean \pm SD) & $(44-97), 68 \pm 11$ \\
\hline SMOT, (range, mean \pm SD) & $(44-91), 68 \pm 12$ \\
\hline SRRB, (range, mean $\pm \mathrm{SD}$ ) & $(45-100), 69 \pm 13$ \\
\hline SRS T score, (range, mean \pm SD) & $(45-100), 68 \pm 12$ \\
\hline \multicolumn{2}{|l|}{ Autism Diagnostic Observation Schedule (ADOS) } \\
\hline Social communication (range, mean \pm SD) & $(3-21), 11 \pm 5$ \\
\hline Language and communication (range, mean \pm SD) & $(1-8), 4 \pm 2$ \\
\hline Reciprocal social interactions (range, mean \pm SD) & $(1-14), 7 \pm 3$ \\
\hline
\end{tabular}

$I Q$ intelligence quotient, CCA-LS structural language, CCA-PS pragmatic behavior, CCA-SE social engagement, SAWR social awareness, SCOG social cognition, SCOM social communication, SMOT social motivation, SRRB restricted interests and repetitive behaviors, SRS T score SRS total score

presence of an activating killer-cell immunoglobulin-like receptor (KIR)/HLA complex that could promote immune activation in ASD. Nevertheless, the scarcity of NK-cell studies in adult patients [25] prompted us to evaluate their characteristics in a cohort of adults with hf-ASD.

\section{Methods and materials Participants}

Thirty-five adults with hf-ASD, meeting DSM-IV TR or DSM-5 criteria for ASD [26], were systematically recruited under the framework of the French InFoRAutism cohort [27], a bi-centric study. Patients were assessed at inclusion and at two subsequent time points, 12 and 24 months, in two expert centers for ASD under the auspices of the Fondation FondaMental (Créteil and Bordeaux, France) (Table 1). A total IQ score above 70, as assessed with the Wechsler Adult Intelligence Scale (WAIS-III or WAISIV), was categorized as high-functioning [28]. Exclusion criteria for patients with hf-ASD were genetic disorders that could generate autism symptomatology (i.e., Angelman syndrome, tuberous sclerosis, fragile $\mathrm{X}$ syndrome) and active neurological disorders (e.g., seizure disorders). Adults with ASD were assessed with standardized diagnostic tools, including the French version of the Autism Diagnostic Interview-Revised (ADI-R) and the Autism Diagnosis Observational Schedule (ADOS) [29]. 

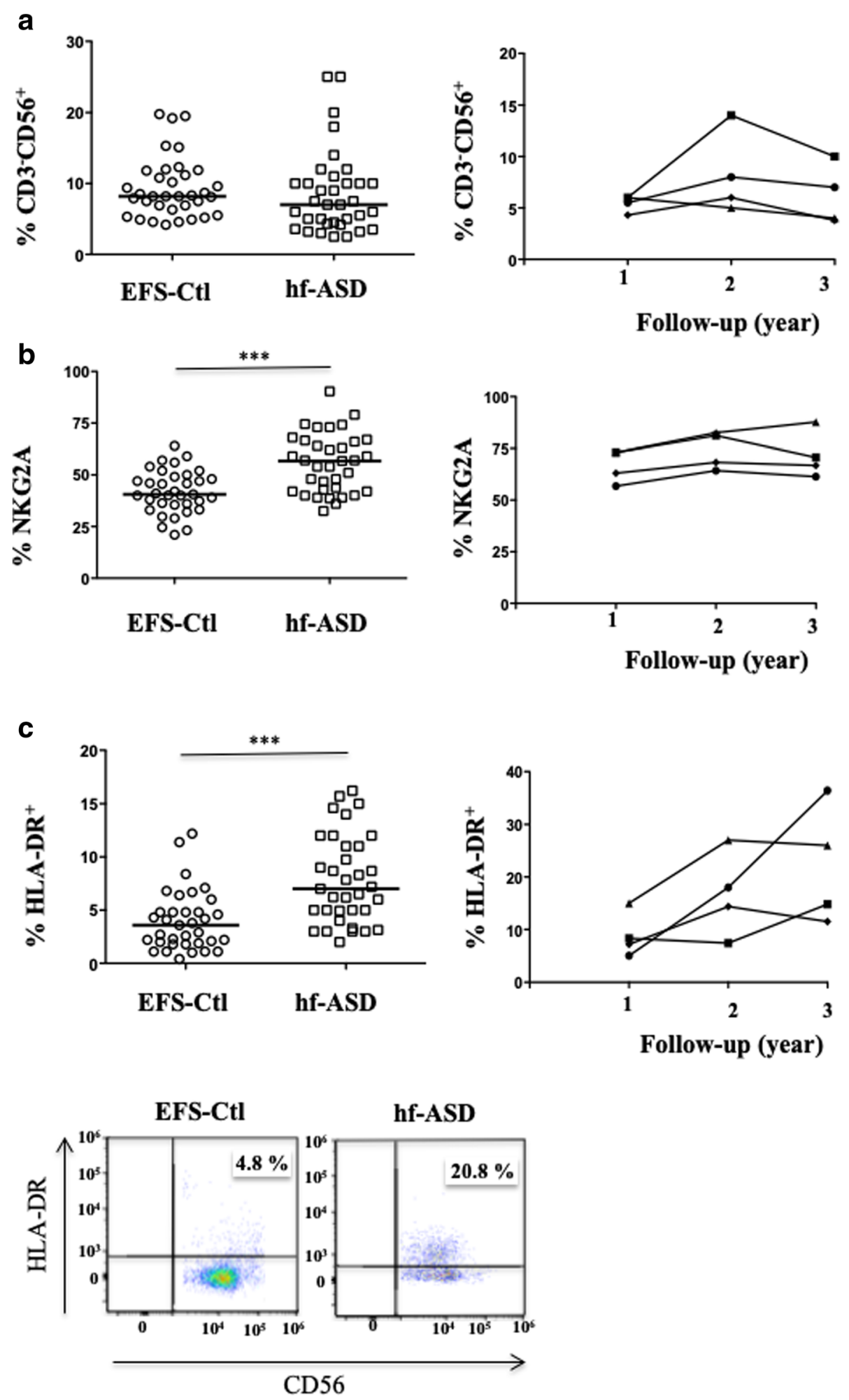

Fig. 1 Extensive phenotypic analysis of NK cells in patients with hf-ASD. a The frequency of $C D 3^{-} C D 56^{+}$cells within the CD45 lymphocyte gate in 35 patients with hf-ASD and 35 age- and sex-matched healthy controls from the French National Blood Service (EFS-Ctl), with a follow-up over a 3-year period in four hf-ASD patients. $\mathbf{b}$ The frequency of the immature marker, NKG2A, within the $\mathrm{CD}^{-} \mathrm{CD}^{-} 6^{+}$NK cells gate in 35 patients with hf-ASD and 35 EFS-Ctl, * $p<0.05$ (Mann-Whitney test), and the follow-up during a 3-year period in four hf-ASD patients. c The frequency of the late activation marker HLA-DR in 35 patients with hf-ASD and 33 EFS-Ctl, ${ }^{* *} p<0.0001$ (Mann-Whitney test). Representative samples are shown in the right panels 
Social and communication scores, core dimensions of ASD symptomatology, were also rated using the Social Responsiveness Scale (SRS) and the Communication Checklist for Adults (CCA), respectively [30, 31]. The SRS scale generates five sub-scores evaluating different aspects of social interaction: social awareness (SAWR), social cognition (SCOG), social communication (SCOM), social motivation (SMOT), and restricted interests and repetitive behaviors (SRRB) (Table 1). The CCA yields three composite scores measuring different aspects of communication, namely language structure, pragmatic skills, and social engagement.

Two consecutive groups of controls were included and tested for their NK-cell signature. We started the study by analyzing control samples recruited under the framework of the InfoR program (InFoR-Ctl). This cohort consisted of 25 individuals selected only based on the absence of personal and familial psychiatric disorders, without any criteria to assess somatic disorders likely related to immune dysfunction, including history of infections and/or presence or history of immune/autoimmune disorders (see Additional file 1: Table S1). As we rapidly observed that NK cells belonging to this cohort presented immune abnormalities, we decided to introduce and use control samples belonging to a pool of over 250 anonymous individuals from the French National Blood Bank (EFS, Paris, France), called EFS-Ctl, currently used as the standard for the routine biological diagnosis of NK lymphoproliferative diseases (i.e., LGL, leukemia, etc.) and for other related immune disorders in the Department of Immunology of the Pitié-Salpêtrière hospital as previously described [32-34]. These blood samples were certified for their absence of common viral infections (i.e., HIV-1 and 2 , hepatitis $B$ and $C$ viruses) and lymphocyte dysfunction (absolute value and frequency of subpopulation, activation status) (https://www.legifrance.gouv.fr/eli/arrete/2016/4/ 5/AFSP1608360A/jo/texte). From these EFS samples, 35 sex- and age-matched EFS-Ctl were randomly selected and served as controls in all experiments.

The study was approved by local Ethical Committees and registered in the public trials registry (NCT02628808). All study participants gave their informed written consent for inclusion in this study.

\section{HLA and KIR genotyping}

HLA and KIR experiments were performed on DNA extracted from total peripheral blood mononuclear cells

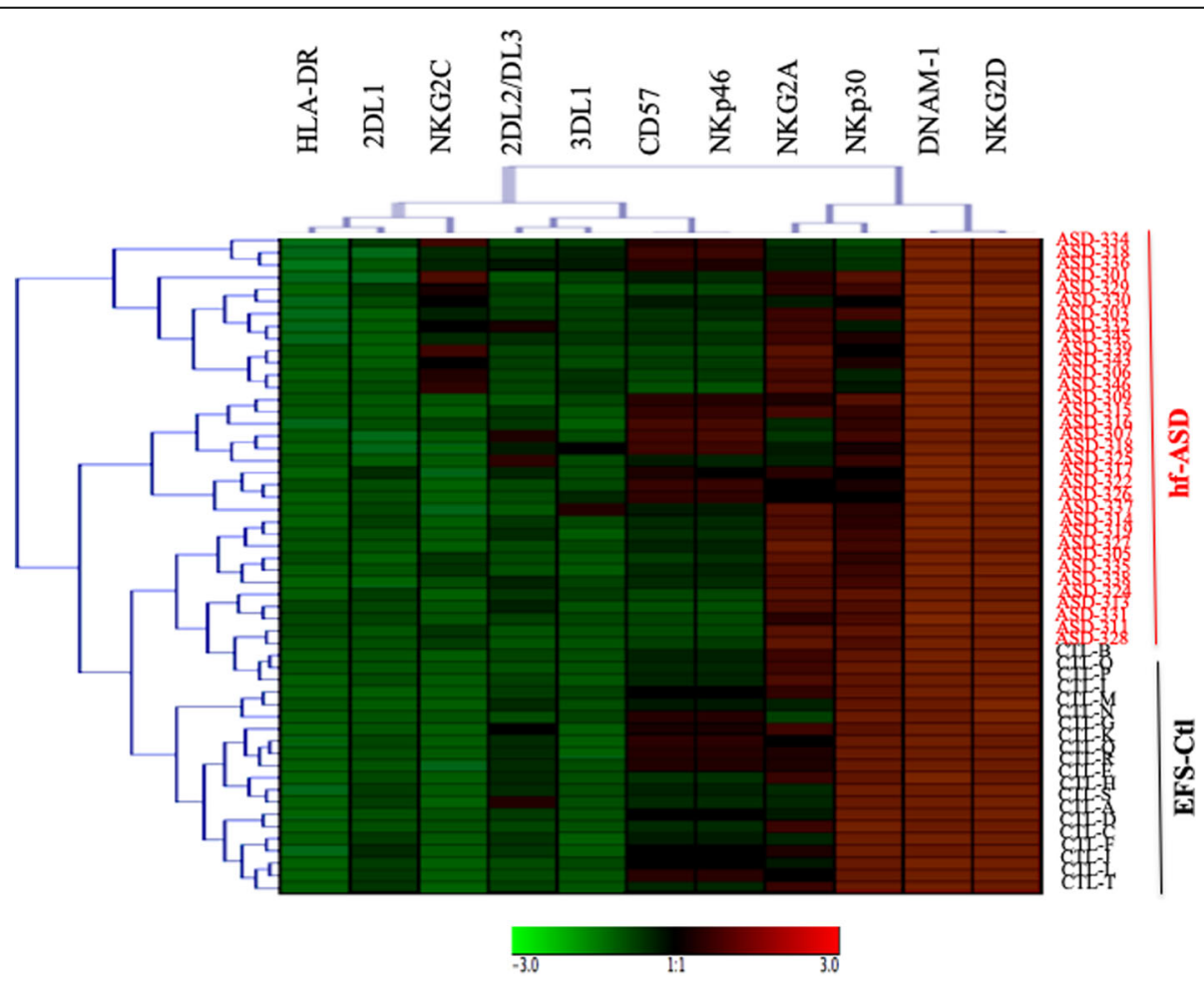

Fig. 2 Hierarchical clustering analysis of 11 NK-cell markers in 34 patients with ASD and 20 age- and sex-matched healthy controls from the French National Blood Service (EFS-Ctl). Each column is dedicated to a distinct NK marker. The color of each square reflects the percentage of expression of the corresponding marker in each individual. The values measured for all samples were color-displayed and rank-ordered considering the healthy donors' median as a reference: green indicates inferior to median, and red indicates superior to median with values that ranged between -3 and +3 . The analysis was performed with the GENESIS program (available at http://www.genome.turgaz.at) 

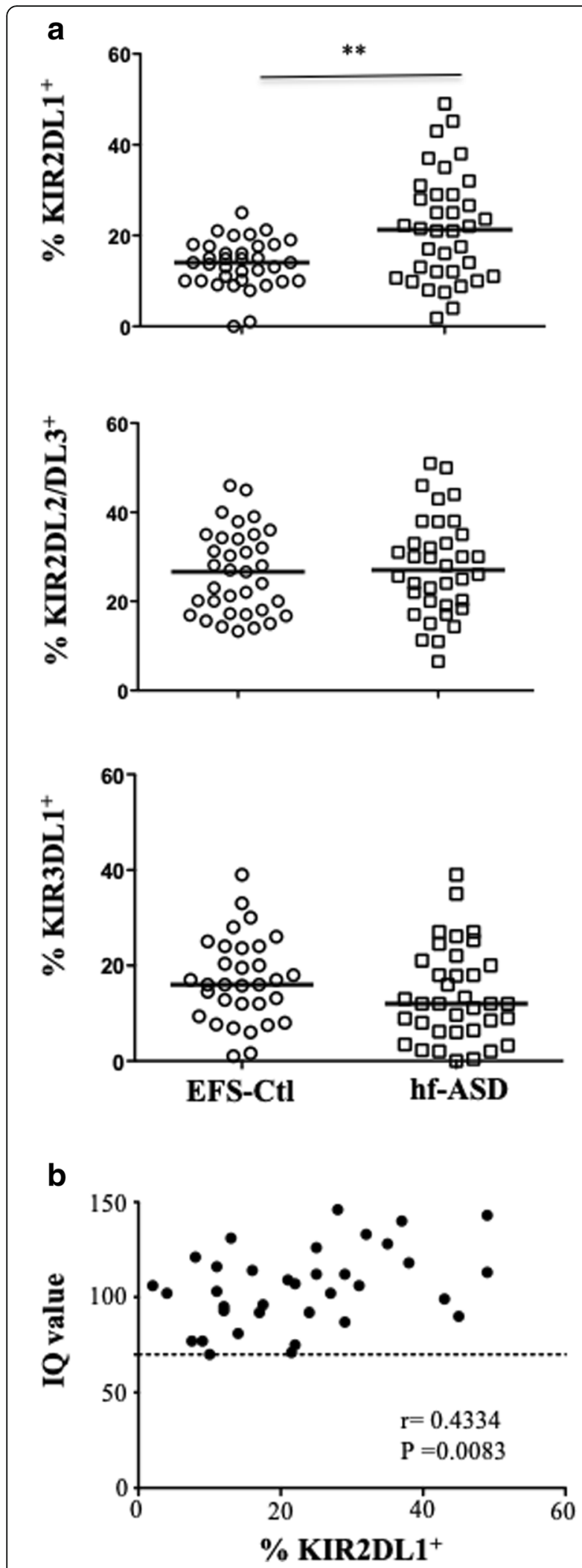

Fig. 3 The association of KIR2DL1 expression and intelligence quotient (IQ) score in patients with hf-ASD. a The frequency of $\mathrm{KIR} 2 \mathrm{DL} 1^{+}, \mathrm{KIR} 2 \mathrm{DL} 2 / 2 \mathrm{DL} 3^{+}$, and $\mathrm{KIR} 3 \mathrm{DL} 1^{+}$cells gated on $\mathrm{CD}^{-} \mathrm{CD}^{-} 6^{+}$ NK cells from 35 patients with ASD and 35 age- and sex-matched healthy controls from the French National Blood Service (EFS-CtI), $p$ $<0.05$ (Mann-Whitney test). $\mathbf{b}$ The correlation between KIR2DL1 ${ }^{+} \mathrm{NK}$ cells in 35 ASD patients and IQ score. The dotted line indicates that IQ values were equal to 70

(PBMCs). HLA genotyping was performed using PCRsequence-specific oligonucleotide (SSO) Luminex LABTYPE SSO kits designed to recognize all the broad specificities. The Luminex 100 flow analyzer identified HLA alleles via HLA visual 1.0 software, by referring to HLA typing template data for the studied loci, as provided by the manufacturer (OneLambda, Inc., CA). KIR genotyping was performed by $\mathrm{PCR}$, using a combination of specific oligonucleotide primers and internal controls, as previously described [35].

\section{Flow cytometry analyses}

NK-cell subsets were analyzed by flow cytometry within the $\mathrm{CD} 45^{+}$lymphocyte population (anti-CD45-Chrome Orange; \#J33), gated on the $\mathrm{CD}^{-}$(anti-CD3-ECD; \#UCHT1) and CD56 ${ }^{+}$(anti-CD56-PC7; \#N901) population, with an appropriate cocktail of 11 antibodies, including anti-CD159a/NKG2A-APC (\#Z199); anti-CD335/ NKp46-APC (\#BAB281); anti-NKG2D-APC; (\#ON72); anti-HLA-DR-PE (\#Immu357); anti-CD57-FITC (\#S-HCL-1) from Coulter, DNAM-1-FITC (\#DX11) from Becton Dickinson, anti-CD337/NKp30-PE (\#AF29-4D12), and anti-KIR2DL2/KIR2DL3-APC (\#DX27) from Miltenyi Biotech; anti-NKG2C-PE (\#134591); anti-KIR2DL1-FITC (\#143211); and anti-KIR3DL1-APC (\#DX9) from R\&D systems.

At least $10,000 \mathrm{CD}^{2} 5^{+} \mathrm{CD}^{-} \mathrm{CD}^{-} 6^{+}$cells were analyzed on a Gallios cytometer (Beckman Coulter). Expression of each marker was measured as a percentage of the total $\mathrm{CD}^{-}{ }^{-} \mathrm{CD} 56^{+} \mathrm{NK}$ cells, as described earlier [36]. A hierarchical clustering was applied for the $11 \mathrm{NK}$ cell-specific phenotypic markers, with the results displayed using the GENESIS program (software available at www.genome.tugraz.at), as described previously [37, 38].

\section{Serology of cytomegalovirus and other pathogens}

Cytomegalovirus (CMV) immunoglobulin (Ig)G serology was analyzed for the $35 \mathrm{hf}$-ASD subjects, using a Luminex-based technology (Bioplex 2200 ToRC IgG Reagent Pack), according to the manufacturer's instructions. A confirmatory assessment of the CMV status, together with the serological screening for 23 other common pathogens, was performed for ASD subjects and EFS-Ctl controls using commercially available ELISA kits (see Additional file 1: methods). 

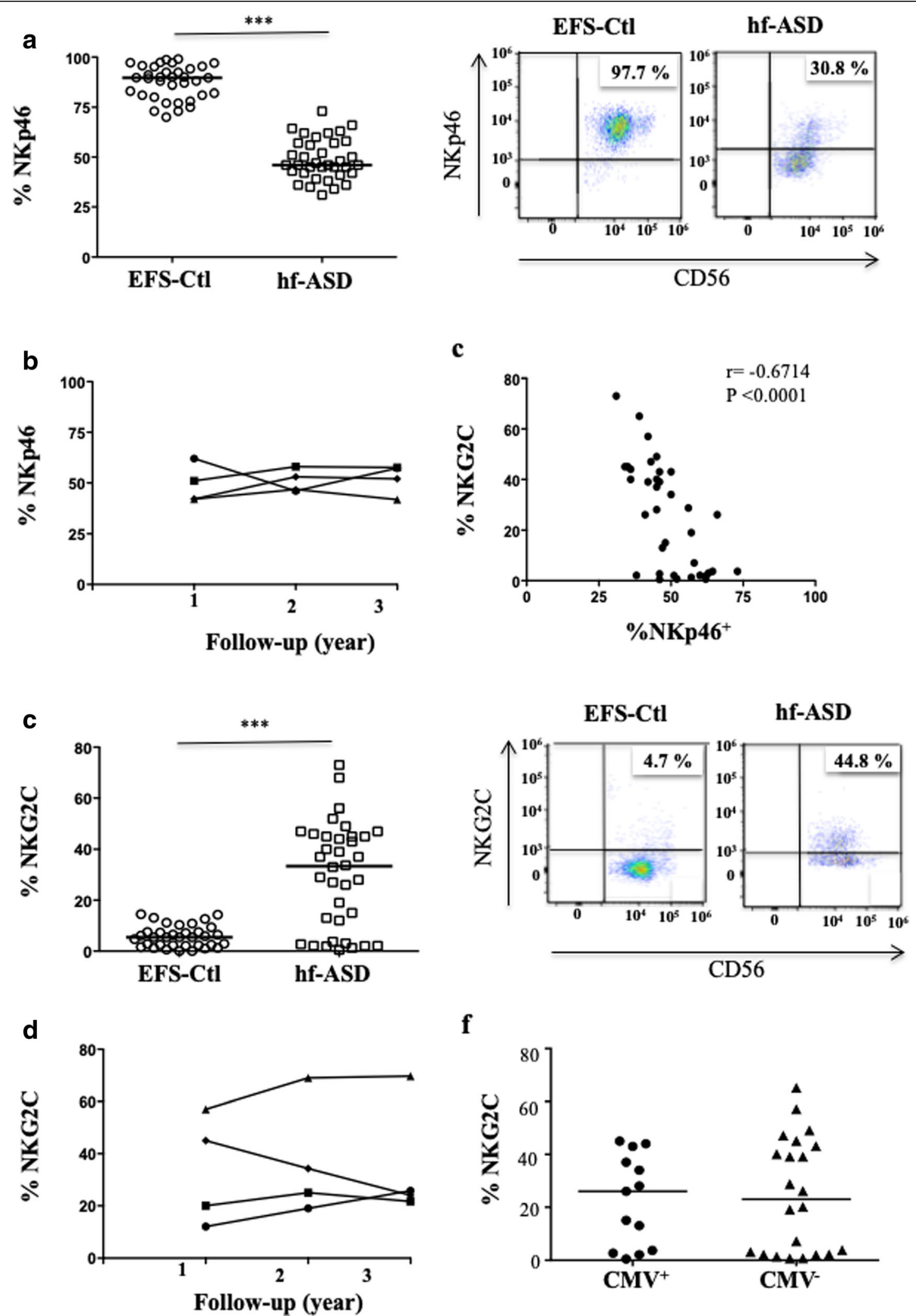

f

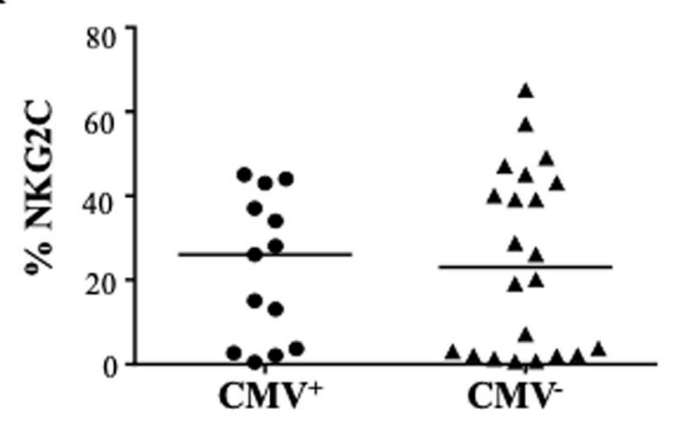

Fig. 4 (See legend on next page.) 
(See figure on previous page.)

Fig. 4 The atypical expansion of NKG2C $C^{+} \mathrm{NK}$ cells in patients with hf-ASD. a The frequency of NKp46 ${ }^{+}$cells gated on $\mathrm{CD}^{-} \mathrm{CD}^{-} 6^{+} \mathrm{NK}^{-}$cells in 35 ASD patients and 35 age- and sex-matched healthy controls from the French National Blood Service (EFS-Ctl), ${ }^{* *} p<0.0001$ (Mann-Whitney test). Representative samples in right panels. $\mathbf{b}$ The follow-up of NKp46 frequency on CD3 ${ }^{-}$CD56 ${ }^{+}$NK cells over a 2-year period in four hf-ASD patients. c The correlation between NKG2C and NKp46 in NK cells in 35 hf-ASD patients. $\mathbf{d}$ The frequency of NKG2C ${ }^{+}$cells gated on $\mathrm{CD}^{-} \mathrm{CD} 56^{+} \mathrm{NK}$ cells in 35 hf-ASD patients and 35 EFS-Ctl, ${ }^{*} p<0.05$ (Mann-Whitney test). Representative samples are shown the in right panels. e The follow-up of NKG2C frequency on $\mathrm{CD}^{-} \mathrm{CD}_{56}{ }^{+} \mathrm{NK}$ cells over a 2-year period in four hf-ASD patients. $\mathbf{f}$ NKG2C expression on NK cells in CMV seronegative $(n=22)$ and seropositive patients $(n=13)$

\section{Degranulation and intracellular production of cytokines}

NK cell degranulation was investigated using assays that were able to detect the CD107a marker, on either overnight-cultured PBMCs in the presence of IL-12 (10 $\mathrm{ng} / \mathrm{ml})$ plus IL-18 $(100 \mathrm{ng} / \mathrm{ml})$ or on PBMCs incubated with K562 target cells, at an effector to target (E:T) cell ratio of 1:1 [32]. Cells were incubated in the presence of an anti-CD107a monoclonal antibody (mAb) (FITC; \#H4A3; Becton Dickinson) for $1 \mathrm{~h}$, followed by a 5 - $\mathrm{h}$ incubation after the addition of Golgi Stop and Golgi Plug solutions (BD Biosciences). For the analysis of intracellular cytokine production, cells were stained with cell-surface markers (anti-CD3 and anti-CD56 mAbs), fixed, permeabilized with a cytofix/cytoperm kit (Becton Dickinson), and then stained with mAbs for anti-IFN- $\gamma$ (Alexa Fluor 700; \#B27; Becton Dickinson) and anti-TNF- $\alpha$ mAbs (eFluor450; \#Mab11; eBiosciences), as previously described [34, 39].

\section{Statistical analysis}

Statistical analyses were performed with Prism- 5 software (GraphPad Software). The nonparametric Mann-Whitney tests were performed for individual comparisons of unrelated samples from hf-ASD patients and EFS-Ctl. Nonparametric correlations were assessed by the determination of the Spearman's rank correlation coefficient. Linear regressions models were used to explore associations between NKG2A; KIR2DL1; NKG2C; HLA-DR; NKp46; and CD107a with age, sex, CCA, SRS, and IQ. Analyses were conducted using Stata 13.

\section{Results}

\section{NK-cell signature in hf-ASD patients}

The present study was conducted on 35 adults with hf-ASD and 35 age- and sex-matched healthy controls, EFS-Ctl (Table 1). The distribution of $\mathrm{CD}^{-}{ }^{-} \mathrm{CD} 56^{+} \mathrm{NK}$ cells, as measured by flow cytometry, was comparable in hf-ASD patients and EFS-Ctl controls at inclusion and during the follow-up period (Fig. 1a), which agreed with data from previous studies $[16,17]$. In addition, the analysis of the CD56 $6^{\mathrm{dim}}$ and the CD56 ${ }^{\text {bright }}$ subsets showed a normal distribution of the two subsets, except for a few CD56 $^{\text {bright }}$ (see Additional file 1: Figure S1a). However, the frequency of NK cells expressing the immature marker, NKG2A, was significantly increased in patients with hf-ASD $(p=0.01)$, as compared to EFS-Ctl at inclusion, and it remained elevated over the 2-year follow-up period (Fig. 1b).

Importantly, the frequency of NK cells expressing the late cell-activation marker, HLA-DR, was significantly increased in patients with hf-ASD compared to the EFS-Ctl control group $(p<0.0001)$ (Fig. 1c). In the four tested hf-ASD patients that were observed over the follow-up period, the high expression level was stable, or slightly increased, both in CD56 ${ }^{\mathrm{dim}}$ and CD56 ${ }^{\text {bright }} \mathrm{NK}$ cell compartments (see Additional file 1: Figure S1b), but not in the $\mathrm{CD}^{+} \mathrm{T}$ and $\mathrm{CD} 19^{+} \mathrm{B}$ cell subsets (data not shown), indicating that lymphocyte activation was exclusively restricted to the NK cells.

To further investigate the NK cell-activation status, a large-scale flow-cytometric analysis of the frequency of 11 NK-cell markers was first carried out (Fig. 2). A hierarchical clustering analysis of the data revealed that the expression pattern of NK cells in hf-ASD patients was distinct from that observed in EFS-Ctl (Fig. 2), suggesting a specific hf-ASD NK-cell phenotype. This analysis also revealed a specific clustering of the HLA-DR, KIR2DL1, and NKG2C markers (Fig. 2). More precisely, when hf-ASD was compared to EFS-Ctl, KIR2DL1 was significantly increased $(p=0.005)$, while KIR2DL2/DL3 and KIR3DL1 were unchanged (Fig. 3a). Of note, and in agreement with previous studies [14], some activating KIR genes (KIR2DS2 and KIR2DS3) were observed more in hf-ASD patients than in EFS-Ctl (see Additional file 1: Table S2). More importantly, the modulation of inhibitory KIR receptors and their ligands (HLA-C1, C2, or Bw4) was not found predictable by any KIR or HLA genetic profile, both in hf-ASD and EFS-Ctl (see Additional file 1: Table S2).

We next investigated an extended panel of activating NK receptors. Most of these NK cell-activating receptors, such as CD57, NKp30, NKG2D, and DNAM-1, were similarly expressed in NK cells from hf-ASD patients and the EFS-Ctl group (see Additional file 1: Figure S2). In contrast, Fig. 4a shows that NKp46 exhibit lower expression levels in hf-ASD patients compared to EFS-Ctl $(p<0.0001$; Fig. 4a), during the follow-up period (Fig. 4b), and more specifically in the CD56 ${ }^{\mathrm{dim}}$ NK-cell subset (see Additional file 1: Figure S1c). However, NKp46 expression 


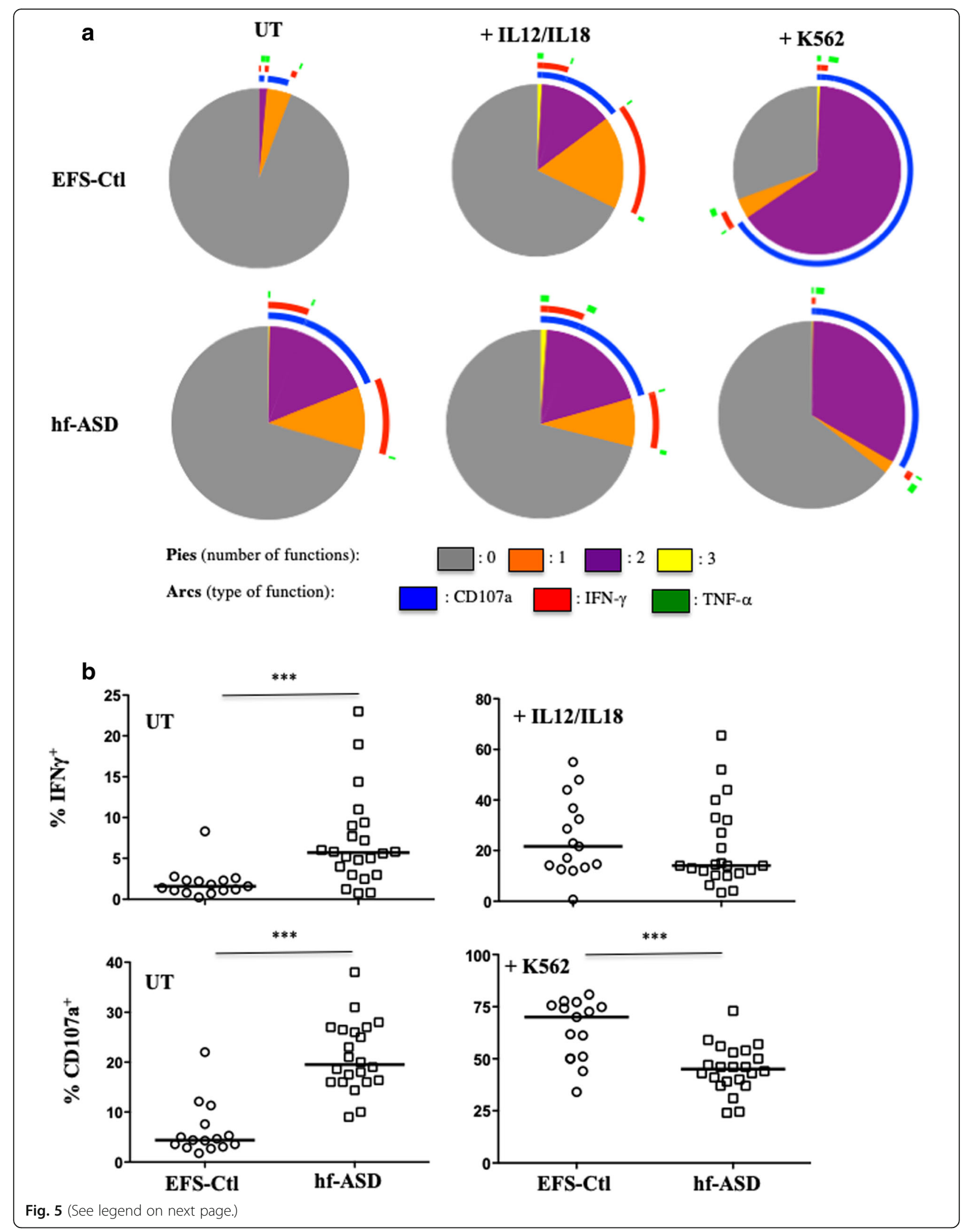


(See figure on previous page.)

Fig. 5 Polyfunctional activity of NK cells from hf-ASD patients. a Polyfunctionality of $\mathrm{CD}^{-} \mathrm{CD}^{-} 6^{+} \mathrm{NK}$ cells (degranulation and production of IFN- $\mathrm{Y}$ and/or TNF-a), 20 patients with hf-ASD (median), compared to 15 age- and sex-matched healthy controls from the French National Blood Service (EFS-CtI, median) at entry. Assays were performed in cells: untreated (UT), IL-12 + IL-18 overnight stimulation, or in the presence of K562 target cells. The values were analyzed with a Boolean gate algorithm (FlowJo; Tree Star, Ashland, OR, USA). Pie and arc charts were generated using SPICE software (National Institute of Allergy and Infectious Diseases freeware). Pies represent the frequency of NK cells positive for 0, 1, 2, or 3 responses (to CD107a, IFN- $\gamma$, and TNF-a). Arcs depict cellular functions as functional or polyfunctional. $\mathbf{b}$ Intracellular of production of IFN- $\gamma$ among UT or IL-12 + IL-18 overnight stimulation, and degranulation of NK cells measured by cell-surface expression of CD107a in CD3 ${ }^{-} \mathrm{CD} 56^{+} \mathrm{NK}$ cells from $22 \mathrm{hf}-\mathrm{ASD}$ patients and $15 \mathrm{EFS}-\mathrm{Ctl}$, tested in absence (UT) or in the presence of the standard K562 target cells (ratio 1:1), ${ }^{* * *} p<0.0001$ (Mann-Whitney test)

was inversely correlated with that of NKG2C, another activating NK receptor $(r=-0.6714 ; p<0.0001$; Fig. $4 \mathrm{c})$. Interestingly, we observed that NKG2C expression was significantly increased in 24 of the $35 \mathrm{hf}-\mathrm{ASD}$ participants, as compared to EFS-Ctl (19-68\% vs $0.0-14.5 \% ; p<0.0001$ in ASD and in EFS-Ctl, respectively) (Fig. 4d). This increased NKG2C expression level remained stable over the follow-up period (Fig. 4e), which is primarily typical of CMV seropositive individuals and to a lesser extent for other viral infections, including HIV-1, hantavirus, chikungunya virus, and viral hepatitis $[33,36]$. Strikingly, NKG2C expression in hf-ASD patients was found to be similar in both CMV seropositive and in seronegative cases (Fig. 4f), likely excluding a CMV-mediated process. Consequently, serum IgG antibodies directed against 23 other common pathogens were screened, with the a priori expectation that no association would be demonstrated. Indeed, only a trend toward an association between the presence of IgG anti-hepatitis A virus, anti-herpes simplex virus (HSV) type 2, and anti-Brucella were observed (see Additional file 1: Table S3). In addition, none of these common pathogens showed a significant correlation with NKG2C expression on NK cells. Overall, the results surprisingly indicate that adults with hf-ASD have an elevated rate of highly activated and dysfunctional NK cells, directly or indirectly triggered by a pathogen, that remains to be determined or merely by another yet to be identified mechanism.

\section{NK-cell functions in hf-ASD patients}

To better understand the possible mechanisms associated with these abnormal immune phenotypes, polyfunctional assays were performed to test the ability of NK cells to simultaneously degranulate and produce cytokines (IFN- $\gamma$ and/or TNF- $\alpha$ ). These assays were carried out in untreated NK cells, in IL-12/IL-18-treated NK cells, and in NK cells after stimulation with K562 target cells. Unexpectedly, the polyfunctional activity of NK cells from hf-ASD patients compared to EFS-Ctl was higher without any treatment (Fig. 5a), including a significant increase in intracellular IFN- $\gamma$ production and a more pronounced degranulation process (Fig. 5b; $p<0.0001$ ). Of note, TNF- $\alpha$ expression was almost undetectable in unstimulated cells of both hf-ASD patients and EFS-Ctl subjects (see Additional file 1: Figure S3a, S3b). It is important to highlight that after IL12/IL18 treatment or stimulation with K562 target cells, as seen in previous studies $[16,17]$, NK cells of hf-ASD patients showed a decrease in IFN- $\gamma$ production and a drastic reduction in degranulation levels compared to EFS-Ctl NK cells, as reflected by the very low levels of the CD107a marker (Fig. $5 \mathrm{a}, \mathrm{b} ; p=0.0008$ for both). Similar profiles of cytokine production and degranulation were observed over the 2-year follow-up period (see Additional file 1: Figure S3c).

Overall, the data indicates an exhaustion status of NK-cell functional responsiveness in patients with hf-ASD, likely associated with a non-stimulated chronic cell-activation state.

\section{Relationship between NK cells and IQ, communication and social scores of hf-ASD}

Only HLA-DR and NKp46 markers were associated with social communication (CCA) and social reciprocity (SRS) scores. A significant correlation was found between NK-HLA-DR expression and both CCA-LS (structural language) $(r=0.48 ; p=0.007)$ and SAWR (social awareness) $(r=0.60 ; p=0.0007)$ scores, while results for NKp46 only approached significance, following

Table 2 Phenotypic and clinical correlations in hf-ASD patients

\begin{tabular}{|c|c|c|c|c|c|c|c|c|c|}
\hline \multirow[b]{2}{*}{ Markers } & \multicolumn{3}{|c|}{ Communication Checklist for Adult scale (CCA) } & \multicolumn{6}{|c|}{ Social Responsiveness Scale (SRS) } \\
\hline & CCA-LS & CCA-PS & CCA-SE & SAWR & SCOG & SCOM & SMOT & SRRB & T score \\
\hline NKp46 & ns & ns & $\begin{array}{l}p=0.03 \\
r=0.4\end{array}$ & $\begin{array}{l}p=0.04 \\
r=0.38\end{array}$ & $\begin{array}{l}p=0.02 \\
r=-0.4\end{array}$ & ns & ns & ns & $\begin{array}{l}p=0.04 \\
r=-0.36\end{array}$ \\
\hline HLA-DR & $\begin{array}{l}p=0.007 \\
r=0.48\end{array}$ & ns & ns & $\begin{array}{l}p=0.0007 \\
r=0.6\end{array}$ & ns & $\begin{array}{l}p=0.01 \\
r=0.44\end{array}$ & ns & ns & ns \\
\hline
\end{tabular}

CCA-LS structural language, CCA-PS pragmatic behavior, CCA-SE social engagement, SAWR social awareness, SCOG social cognition, SCOM social communication, SMOT social motivation, SRRB restricted interests and repetitive behaviors, SRS T score SRS total score, ns non-significant 
multivariate analysis (Table 2). Interestingly, the analysis of potential relationships between IQ scores and NK-cell characteristics showed a statistically significant association with KIR2DL1 (Spearman test; $r=0.4334 ; p=0.008$ ) (Fig. 3b), a finding further confirmed by linear multivariate analysis, adjusting for age and gender (95\% CI [0.1140;0.5272]; $p=0.003$ ).

\section{Discussion}

The present study provides novel insights in the exploration of immune dysfunction in ASD by implicating NK cells in the pathophysiology of adult patients with hf-ASD. In contrast to previously reported data in cohorts of children with ASD [15-17, 24], we observed that the frequency of NK cells in adult patients with hf-ASD tends to remain similar to that of healthy controls. This discrepancy could be related to the age of patients. Indeed, two large-scale studies have quantified the distribution of lymphocyte subsets in the peripheral blood of healthy children and showed that both total NK cell numbers and percentages differ from birth through late adolescence [40, 41]. This variation may be also indicative of the already reported phenotypic differences in NK cells between children and adults [42]. Altogether, these results highlight the importance of considering socio-demographic characteristics of the studied sample before any comparison with other data.

Interestingly, in a substantial proportion of hf-ASD patients (61\% of cases), we found NK cells characterized by the persistence of an uncommon $\mathrm{CD} 56{ }^{\mathrm{dim}} \mathrm{H}$ $\mathrm{LA}^{-D R^{+}} \mathrm{NKG}_{2} \mathrm{C}^{\text {high }} \mathrm{KIR} \mathrm{DL} 1^{+}$phenotype signature. This signature was found to be associated with core ASD clinical dimensions and remained stable during the 2-year follow-up period in the tested samples. These data are highly evocative of a viral pathogenic involvement in ASD risk, since following pathogen exposure, the NK cell repertoire is known to display several distinct characteristics, including expansion of cells expressing the activating NKG2C receptor, a self-specific inhibitory KIR receptor (KIR2DL1), and low expression levels of NKp46 [43]. The expansion of $\mathrm{NKG}_{2} \mathrm{C}^{+} \mathrm{NK}$ cells is most commonly evident in CMV seropositive individuals [43, 44]. In contrast, we observed that the expansion of $\mathrm{NKG}_{2} \mathrm{C}^{+} \mathrm{NK}$ cells occurred irrespective of their CMV status in our sample of patients with hf-ASD. Although the differentiation and proliferation of $\mathrm{NKG}_{2} \mathrm{C}^{+} \mathrm{NK}$ cells in ASD requires further investigation, the present results may indicate a yet to be identified ASD-specific pathogen driving $\mathrm{NKG}_{2} \mathrm{C}^{+}$receptor overexpression. As several studies implicate pre-, peri-, and postnatal infections for ASD risk [6-9, 45], the present data gives some support to non-resolved infectious events in ASD, possibly arising from suboptimal, genetically-determined, anti-infectious responses, and/or from other ASD-related processes. A permanent state of NK cell activation and inflammation, possibly having deleterious central nervous system (CNS) consequences, may arise from this hyper-activation.

The other observation that deserves to be highlighted pertains to the abnormal ability of adult hf-ASD NK cells to degranulate and to produce abnormal amounts of IFN- $\gamma$ at a steady state level, while becoming hypofunctional/exhausted when challenged by treatment with IL-12/IL-18 or stimulation with K562 target cells. Such characteristics have been shown to occur during childhood in patients with ASD [15-17, 24], as well as in a range of other psychiatric disorders, including obsessive-compulsive disorder, chronic stress, and depression [46, 47], all reflecting alterations in systemic NK cell activity. The presence of NK cells in the CNS may suggest more direct central effects of their dysfunctions, whose exploration will require further investigation [48].

The state of NK cell exhaustion in adults with hf-ASD may be due to heightened levels of peripheral NK cell inflammation/activation, in accordance with the "discontinuity theory" [49], in which the immune system responds adequately to sudden changes in antigenic stimulation but becomes tolerant after slow or continuous stimulations. This could also merely reflect abnormal ontogenetic development of the CD $56^{\text {bright }}$ and CD56 ${ }^{\text {dim }}$ subsets of NK cells, given their respective capacity of cytokine production and cytotoxicity, with implication in ASD development. This is likely reflected by the trends observed on associations between elevated levels of activated HLA-DR ${ }^{+}$NK cells and core phenotypic dimensions of hf-ASD, especially structural language (CCA-LS) and social awareness (SAWR), which implicates alterations in NK-cell functioning in ASD. Such data may also fit well with wider observations, including: (1) previous psychobiological models linking inflammation, lower social status, poor physical status, and emotional distress [50]; (2) ligands of the activating NKG2D NK-cell receptor are expressed in neuronal stem cells; and (3) NK cells are essential for normal brain development. Hence, any functional impairment of NK cells during critical neurodevelopmental windows may affect neurogenesis, resulting in adverse consequences for brain development [51, 52].

Finally, according to the fine-tuned equilibrium between inhibitory and activating NK cell receptors, the observed high expression of the inhibitory KIR2DL1 receptor (for which HLA-C2 is a natural ligand) and its relationship with IQ, fits to the known relationship between ASD and HLA alleles [53, 54], as well as to the genetic association between major histocompatibility complex single nucleotide polymorphisms and IQ scores in ASD [52]. Other studies showed that the frequency of several activating KIR genes and their cognate HLA 
ligands is higher in ASD children and their mothers $[55,56]$. Furthermore, the low-expressor genotype of the immuno-modulatory non-classical HLA-G was consistently found to be more prevalent in ASD patients belonging to different population groups [57-59]. Altogether, the finding of this study reinforces the abovementioned genetic link established with the commonly observed immune activation status in ASD. Given that, it will be of interest in future studies to investigate the presence of such correlations in cohorts of adult and children with hf- and non-hf-ASD.

Overall, the permanent activation of NK cells in ASD may contribute to a vicious cycle of persistent degranulation potential, heightened inflammation, and neuro-immune damage and dysfunction.

\section{Limitations}

This study stressed the importance of a fine-tuned design for the inclusion criteria of controls in the immune analysis of psychiatric disorders. Indeed, in psychiatric studies, controls are usually included according to the absence of psychiatric conditions using only after psychiatric assessments without any biological and/or somatic screening. By contrast, in immunological settings, controls are included based on the strict absence of any abnormality concerning either biological markers of immune dysfunction(s) or the existence of any past and present immune disorders but without any assessment of psychiatric disorders. In France, according to the international requirements, immunological analysis is always based on a comparison of patients' samples with certified samples of healthy donors from blood banks, i.e., EFS. Our observations reveal, for the first time, a dysfunction of the NK cell compartment in a subgroup of patients with ASD. It will thus be important to replicate these results in future studies with new cohorts of patients, matched with healthy donors, screened both for neuropsychiatric and immune disorders.

\section{Conclusions}

The data presented here demonstrates that a chronic NK cell inflammatory/activation process in adult hf-ASD is associated with core autism symptomatology. The early developmental etiopathogenesis that drives these long-lasting changes, as well as a better understanding of such pathophysiological processes that occur later in life in patients with ASD, may help in the development of new targets for therapeutic interventions.

\section{Additional file}

Additional file 1: Table S1. Baseline characteristics of $\mathrm{CD}^{-} \mathrm{CD}^{-} 6^{+} \mathrm{NK}$ cells from the InFoR and EFS control groups. Table S2. KIR/HLA genotypes and HLA-ligand combinations in hf-ASD patients, compared with controls from EFS. Table S3. IgG serology test of different pathogens in hf-ASD patients and controls from EFS. Figure S1. Phenotypic expression of CD56 ${ }^{\mathrm{dim}}$ and CD56 ${ }^{\text {bright }} \mathrm{NK}$ cell subsets from patients with hfASD. Figure S2. Expression of supplementary cell-surface markers in NK cells from patients with hf-ASD. Figure S3. Functional activity of NK cells from patients with hf-ASD. (DOCX $6113 \mathrm{~kb})$

\section{Abbreviations}

ASD: Autism spectrum disorders; CMV: Cytomegalovirus; Ctl: Control; DSM-5: Diagnostic and Statistical Manual of Mental Disorders, Fifth Edition; EFS: French National Blood Service; hf-ASD: High-functioning ASD; IFNY: Interferon-gamma; IL: Interleukin; IQ: Intelligence quotient; mAb: Monoclonal antibody; NK: Natural killer; PBMCs: Peripheral blood mononuclear cells; TNF-a: Tumor necrosis factor-alpha

\section{Acknowledgements}

We are very grateful to Prof Hemmo Drexhage (Erasmus University Rotterdam, Immunology Department, Nederland) for helpful discussions and critical review of the manuscript We also thank all of the clinicians and patients who participated in this study, and more particularly to the following French organisms and establishments: AP-HP, Charles Perrens hospital (Bordeaux), Robert Debré hospital (Paris), and CIC Henri Mondor (Creteil).

\section{Funding}

Funding was provided from a grant of the French National Agency of Research (ANR) under reference ANR-11-IDEX-0004-02. This study was also supported by the Centre National de la Recherche Scientifique, the Fondation pour la Recherche Médicale, the Labex Bio-PSY and BRAIN, and the Ministère de l'Enseignement supérieur et de la Recherche. The content is solely the responsibility of the authors and does not necessarily represent the official views of the founders.

\section{Availability of data and materials}

The datasets used and analyzed during the current study are available from the corresponding author on reasonable request.

\section{Authors' contributions}

$M B$ and NT performed most of the experiments and analyzed the data. AG, $I S, A B, M B, R D$, and $M L$ recruited and enrolled patients and monitored the clinical data. $M B, N T, M L, R T$, and $W$ supervised the experiments and interpreted the results. RK, PD, MC, SG, and MLL discussed the results. ML, RT, and CS wrote the manuscript. All authors contributed to and approved the final manuscript.

\section{Ethics approval and consent to participate}

This study is part of clinical trial C07-33 sponsored by Inserm. It was granted approval by local Ethics Committee or "Comité de Protection des Personnes" on 2008 November 14th, authorized by the French authorities (ANSM B80738-70 on 2008 August 11th), and registered in a public trial registry (NCT02628808). All study participants gave their informed written consent to participation, in line with French ethical guidelines.

Consent for publication

All authors agreed to this manuscript's publication.

\section{Competing interests}

Myriam Ly Le-Moal is an employee of the Roche Institute. The other authors report no biomedical financial interests or potential conflicts of interest.

\section{Publisher's Note}

Springer Nature remains neutral with regard to jurisdictional claims in published maps and institutional affiliations.

\section{Author details}

${ }^{1}$ INSERM, U1160, Hôpital Saint Louis, Paris, France. 'Fondation FondaMental, Créteil, France. 3Sorbonne Université, UPMC, INSERM U1135, CNRS ERL8255, Centre d'Immunologie et des Maladies Infectieuses (CIMI-Paris), Paris, France. ${ }^{4}$ DHU PePSY, Department of psychiatry, Mondor Hospital, Université Paris Est Créteil, INSERM, U955, Psychiatrie Translationnelle, Créteil, France. ${ }^{5}$ Inserm 
Transfer, Paris, France. ${ }^{6}$ French Institute of Health and Medical Research, Paris, France. ${ }^{7}$ Institut Roche, Boulogne-Billancourt, France. ${ }^{8}$ Institut de Neurosciences Cognitives et Intégratives d'Aquitaine, Université de Bordeaux, Bordeaux, France. ${ }^{9} \mathrm{DHU}$ Protect, Service de Psychiatrie de l'Enfant et de I'Adolescent, Hôpital Robert Debré, Département de Génétique Humaine et Fonctions Cognitives, Institut Pasteur, Paris, France.

\section{Received: 11 January 2019 Accepted: 18 March 2019}

Published online: 15 May 2019

\section{References}

1. Constantino JN, Charman T. Diagnosis of autism spectrum disorder: reconciling the syndrome, its diverse origins, and variation in expression. Lancet Neurol. 2016;15(3):279-91.

2. Lord C, Bishop SL. Recent advances in autism research as reflected in DSM-5 criteria for autism spectrum disorder. Annu Rev Clin Psychol. 2015;11:53-70.

3. Centers for Disease Control and Prevention. Prevalence and characteristics of autism spectrum disorder among children aged 8 years - autism and developmental disabilities monitoring network, 11 sites, United States, 2012. MMWR Surveill Summ. 2016;65(3):1-23.

4. Nevison C, Blaxill M, Zahorodny W. California autism prevalence trends from 1931 to 2014 and comparison to national ASD data from IDEA and ADDM. J Autism Dev Disord. 2018;48(12):4103-17.

5. Chaste P, Leboyer M. Autism risk factors: genes, environment, and geneenvironment interactions. Dialogues Clin Neurosci. 2012;14(3):281-92.

6. Meldrum SJ, Strunk T, Currie A, Prescott SL, Simmer K, Whitehouse AJ. Autism spectrum disorder in children born preterm-role of exposure to perinatal inflammation. Front Neurosci. 2013;7:123.

7. Lee BK, Magnusson C, Gardner RM, Blomström Å, Newschaffer CJ, Burstyn I, et al. Maternal hospitalization with infection during pregnancy and risk of autism spectrum disorders. Brain Behav Immun. 2015;44:100-5.

8. Zerbo O, Yoshida C, Grether JK, Van de Water J, Ashwood P, Delorenze GN, et al. Neonatal cytokines and chemokines and risk of autism spectrum disorder: the Early Markers for Autism (EMA) study: a case-control study. J Neuroinflammation. 2014;11:113.

9. Meltzer Al, Van de Water J. The role of the immune system in autism spectrum disorder. Neuropsychopharmacology. 2017;42(1):284-98.

10. Mitchell RH, Goldstein BI. Inflammation in children and adolescents with neuropsychiatric disorders: a systematic review. J Am Acad Child Adolesc Psychiatry. 2014;53(3):274-96.

11. Campbell DB, Sutcliffe JS, Ebert PJ, Militerni R, Bravaccio C, Trillo S, et al. A genetic variant that disrupts MET transcription is associated with autism. Proc Natl Acad Sci U S A. 2006;103(45):16834-9.

12. Bennabi M, Delorme R, Oliveira J, Fortier C, Lajnef M, Boukouaci W, et al. Dectin-1 polymorphism: a genetic disease specifier in autism spectrum disorders? PLoS One. 2015;10:e0137339.

13. Estes ML, McAllister AK. Immune mediators in the brain and peripheral tissues in autism spectrum disorder. Nat Rev Neurosci. 2015;16(8):469-86.

14. Torres AR, Sweeten TL, Johnson RC, Odell D, Westover JB, Bray-Ward P, et al. Common genetic variants found in HLA and KIR immune genes in autism spectrum disorder. Front Neurosci. 2016;10:463.

15. Warren RP, Foster A, Margaretten NC. Reduced natural killer cell activity in autism. J Am Acad Child Adolesc Psychiatry. 1987;26(3):333-5.

16. Vojdani A, Mumper E, Granpeesheh D, Mielke L, Traver D, Bock K, et al. Low natural killer cell cytotoxic activity in autism: the role of glutathione, $\mathrm{LL}-2$ and IL-15. J Neuroimmunol. 2008;205(1-2):148-54.

17. Enstrom AM, Lit L, Onore CE, Gregg JP, Hansen RL, Pessah IN, et al. Altered gene expression and function of peripheral blood natural killer cells in children with autism. Altered gene expression and function of peripheral blood natural killer cells in children with. Autism. 2009;23(1): 124-33.

18. Patterson PH. Maternal infection and immune involvement in autism. Trends Mol Med. 2011;17:389-94.

19. Orange JS. Natural killer cell deficiency. J Allergy Clin Immunol. 2013;132(3):515-25.

20. Gasser $\mathrm{S}$, Raulet $\mathrm{DH}$. Activation and self-tolerance of natural killer cells. Immunol Rev. 2006;214:130-42.

21. Sun JC, Lanier LL. NK cell development, homeostasis and function: parallels with CD8 ${ }^{+}$T cells. Nat Rev Immunol. 2011;11:645-57.
22. Vivier E, Raulet DH, Moretta A, Caligiuri MA, Zitvogel L, Lanier LL, et al. Innate or adaptive immunity? The example of natural killer cells. Science. 2011;331(6013):44-9.

23. Campbell KS, Hasegawa J. Natural killer cell biology: an update and future directions. J Allergy Clin Immunol. 2013;132(3):536-44.

24. Ashwood P, Corbett BA, Kantor A, Schulman H, Van de Water J, Amaral DG. In search of cellular immunophenotypes in the blood of children with autism. PLoS One. 2011;6(5):e19299.

25. López-Cacho JM, Gallardo S, Posada M, Aguerri M, Calzada D, Mayayo T, et al. Characterization of immune cell phenotypes in adults with autism spectrum disorders. J Investig Med. 2016;64(7):1179-85.

26. American Psychiatric Association. Diagnostic and statistical manual of mental disorders fifth editions (DSMV-5). 2013.

27. Hotier S, Leroy F, Boisgontier J, Laidi C, Mangin JF, Delorme R, et al. Social cognition in autism is associated with the neurodevelopment of the posterior superior temporal sulcus. Acta Psychiatr Scand. 2017; 136(5):517-25.

28. de Giambattista C, Ventura P, Trerotoli P, Margari M, Palumbri R, Margari L. Subtyping the autism spectrum disorder: comparison of children with high functioning autism and Asperger syndrome. J Autism Dev Disord 2019;49(1): 138-150.

29. Lord C, Risi S, Lambrecht L, Cook EH Jr, Leventhal BL, DiLavore PC, Pickles A, Rutter M. The autism diagnostic observation schedule-generic: a standard measure of social and communication deficits associated with the spectrum of autism. J Autism Dev Disord. 2000;30(3):205-23.

30. Constantino JN, Gruber CP, Davis S. The factor structure of autistic traits. J Child Psychol Psychiatry. 2004;45(4):719-26.

31. Whitehouse AJ, Coon H, Miller J, Salisbury B, Bishop DV. Narrowing the broader autism phenotype: a study using the Communication ChecklistAdult Version (CC-A). Autism. 2010;14(6):559-74.

32. Nguyen S, Morel V, Le Garff-Tavernier BF, Leblond V, Debré $P$, et al. Persistence of CD16+/CD56-/2B4+ natural killer cells: a highly dysfunctional NK subset expanded in ocular myasthenia gravis. J Neuroimmunol. 2006; 179(1-2):117-25.

33. Coppo P, Gouilleux-Gruart V, Huang Y, Bouhlal H, Bouchet S, Perrot C, et al. STAT3 transcription factor is constitutively activated and is oncogenic in nasal-type NK/T-cell lymphoma. Leukemia. 2009;23(9):1667-78.

34. Hervier B, Perez $M$, Allenbach $Y$, Devilliers $H$, Cohen-Aubart F, Uzunhan $Y$, et al. Involvement of NK cells, and NKp30 pathway in antisynthetase syndrome. J Immunol. 2016;197(5):1621-30.

35. Vilches C, Castano J, Gomez-Lozano N, Estefanıa E. Facilitation of KIR genotyping by a PCR-SSP method that amplifies short DNA fragments. Tissue Antigens. 2007;70(5):415-22.

36. Achour A, Baychelier F, Besson C, Arnoux A, Marty M, Hannoun L, et al. Expansion of CMV-mediated NKG2C+NK cells associates with the development of specific de novo malignancies in liver-transplanted patients. J Immunol. 2014;192(1):503-11.

37. Sturn A, Quackenbush J, Trajanoski Z. Genesis: cluster analysis of microarray data. Bioinformatics. 2002;18(1):207-8.

38. Petitdemange $C$, Becquart $P$, Wauquier N, Béziat V, Debré $P$, Leroy EM, et al. Unconventional repertoire profile is imprinted during acute chikungunya infection for natural killer cells polarization toward cytotoxicity. PLoS Pathog. 2011;7:e1002268.

39. Baychelier F, Achour A, Nguyen S, Raphael M, Toubert A, Besson C, et al. Natural killer cell deficiency in patients with non-Hodgkin lymphoma after lung transplantation. J Heart Lung Transplant. 2015;34(4):604-12.

40. Comans-Bitter WM, de Groot R, van den Beemd R, Neijens HJ, Hop WC, Groeneveld K, Hooijkaas H, et al. Immunophenotyping of blood lymphocytes in childhood. Reference values for lymphocyte subpopulations. J Pediatr. 1997;130(3):388-93.

41. Shearer WT, Rosenblatt HM, Gelman RS, Oyomopito R, Plaeger S, Stiehm ER, et al; Pediatric AIDS Clinical Trials Group. Lymphocyte subsets in healthy children from birth through 18 years of age: the Pediatric AIDS Clinical Trials Group P1009 study. J Allergy Clin Immunol 2003;112(5):973-980.

42. Le Garff-Tavernier M, Béziat V, Decocq J, Siguret V, Gandjbakhch F, Pautas E, et al. Human NK cells display major phenotypic and functional changes over the life span. Aging Cell. 2010;9(4):527-35.

43. Malmberg KJ, Beziat V, Ljunggren HG. Spotlight on NKG2C and the human NK-cell response to CMV infection. Eur J Immunol. 2012;42(12):3141-5.

44. Virgin HW, Wherry EJ, Ahmed R. Redefining chronic viral infection. Cell. 2009;138(1):30-50. 
45. Mahic M, Mjaaland S, Bøvelstad HM, Gunnes N, Susser E, Bresnahan M, et al. Maternal immunoreactivity to herpes simplex virus 2 and risk of autism spectrum disorder in male offspring. mSphere. 2007;2:e00016.

46. Evans DL, Folds JD, Petitto JM, Golden RN, Pedersen CA, Corrigan M, et al. Circulating natural killer cell phenotypes in men and women with major depression. Relation to cytotoxic activity and severity of depression. Arch Gen Psychiatry. 1992;49(5):388-95.

47. Denys D, Fluitman S, Kavelaars A, Heijnen C, Westenberg H. Decreased TNFalpha and NK activity in obsessive-compulsive disorder. Psychoneuroendocrinology. 2004;29(7):945-52.

48. Poli A, Kmiecik J, Domingues O, Hentges F, Bléry M, Chekenya M, et al. NK cells in central nervous system disorders. J Immunol. 2013;190(11):5355-62.

49. Pradeu T, Jaeger $S$, Vivier $E$. The speed of change: towards a discontinuity theory of immunity? Nat Rev Immunol. 2013;13(10):764-9.

50. Kemeny ME. Psychobiological responses to social threat: evolution of a psychological model in psychoneuroimmunology. Brain Behav Immun. 2009:23(1):1-9.

51. Popa N, Cedile O, Pollet-Villard X, Bagnis C, Durbec P, Boucraut J. RAE-1 is expressed in the adult subventricular zone and controls cell proliferation of neurospheres. Glia. 2011;59(1):35-44.

52. Wang HZ, Qin HD, Guo W, Samuels J, Shugart YY. New insights into the genetic mechanism of $\mathrm{IQ}$ in autism spectrum disorders. Front Genet. 2013;4:195

53. Geschwind DH, State MW. Gene hunting in autism spectrum disorder: on the path to precision medicine. Lancet Neurol. 2015;14(11):1109-20.

54. Ansel A, Rosenzweig JP, Zisman PD, Melamed M, Gesundheit B. Variation in gene expression in autism spectrum disorders: an extensive review of transcriptomic studies. Front Neurosci. 2017;10:601

55. Torres AR, Westover JB, Gibbons C, Johnson RC, Ward DC. Activating killercell immunoglobulin-like receptors (KIR) and their cognate HLA ligands are significantly increased in autism. Brain Behav Immun. 2012;26(7):1122-7.

56. Guerini FR, Bolognesi E, Chiappedi M, Manca S, Ghezzo A, Agliardi C, et al. Activating KIR molecules and their cognate ligands prevail in children with a diagnosis of ASD and in their mothers. Brain Behav Immun. 2014;36:54-60.

57. Guerini FR, Bolognesi E, Chiappedi M, Ghezzo A, Manca S, Zanette M, et al. HLA-G*14bp insertion and the KIR2DS1-HLAC2 complex impact on behavioral impairment in children with autism spectrum disorders. Neuroscience. 2018:370:163-9.

58. Guerini FR, Bolognesi E, Chiappedi M, Ripamonti E, Ghezzo A, Zanette M, et al. HLA-G coding region polymorphism is skewed in autistic spectrum disorders. Brain Behav Immun. 2018;67:308-13.

59. Guerini FR, Bolognesi E, Sotgiu S, Carta A, Clerici C, Chiappedi M, et al. HLA$G$ allelic distribution in Sardinian children with autism spectrum disorders: a replication study. Brain Behav Immun. 2019. https://doi.org/10.1016/j.bbi. 2019.02.003

Ready to submit your research? Choose BMC and benefit from:

- fast, convenient online submission

- thorough peer review by experienced researchers in your field

- rapid publication on acceptance

- support for research data, including large and complex data types

- gold Open Access which fosters wider collaboration and increased citations

- maximum visibility for your research: over $100 \mathrm{M}$ website views per year

At $\mathrm{BMC}$, research is always in progress.

Learn more biomedcentral.com/submissions 